\title{
Mice Lacking Fatty Acid-Binding Protein 5 Are Resistant to Listeria monocytogenes
}

\author{
Deviyani M. Rao Della T. Phan Michelle J. Choo Amie L. Owen \\ Anne-Laure Perraud Fabienne Gally \\ Department of Biomedical Research, National Jewish Health, Denver, CO, USA
}

\section{Keywords}

FABP5 - Macrophages · Listeria monocytogenes infection

\begin{abstract}
To investigate the role of fatty acid-binding protein 5 (FABP5) in infectious diseases, FABP5-deficient mice were challenged with Listeria monocytogenes, a facultative intracellular bacterial pathogen. Interestingly, FABP5-deficient animals were able to clear the infection within 3 days whereas control wild-type (WT) animals showed comparatively higher bacterial burdens in the liver and spleen. Sections of infected tissues showed an increase in inflammatory foci in WT mice compared to FABP5-deficient mice. FABP5-deficient mice had lower circulating inflammatory cytokines and increased inducible nitric oxide synthase production. FABP5-deficient mouse bone marrow-derived macrophages produced higher levels of nitrite anion than their WT counterparts in response to various stimuli. Additionally, in contrast to $\mathrm{FABP5}^{-/-}$mice, transgenic mice overexpressing FABP5 in myeloid cells (LysM-Cre driven) showed decreased survival rates and increased bacterial burden and inflammatory cytokines. Overall, these findings suggest that increased FABP 5 levels correlate with a higher L. monocytogenes bacterial burden and elevated subsequent inflammation.
\end{abstract}

(c) 2019 The Author(s)

Published by S. Karger AG, Basel

\section{KARGER}

E-Mail karger@karger.com www.karger.com/jin

\section{(C) 2019 The Author(s)}

Published by S. Karger AG, Basel

Karger

Open access

This article is licensed under the Creative Commons AttributionNonCommercial-NoDerivatives 4.0 International License (CC BY NC-ND) (http://www.karger.com/Services/OpenAccessLicense). Usage and distribution for commercial purposes as well as any distribution of modified material requires written permission.

\section{Introduction}

Listeria monocytogenes is a facultative intracellular Gram-positive bacterium responsible for listeriosis. This bacterium is one of the most virulent food-borne pathogens with fatality rates as high as $20-30 \%$ in high-risk individuals, and the third-most common cause of meningitis in newborns. Host cell invasion by this bacterium occurs via phagocytosis or pathogen-induced endocytosis in hepatocytes, neurons, epithelial cells, endothelial cells and fibroblasts [1]. Mouse models of L. monocytogenes infection have been critical for our understanding of the immune system's response to intracellular bacterial infections [2]. These models have been instrumental in showing that macrophages are critical in the early stages of infection [3] by producing reactive nitrogen species, reactive oxygen species (ROS), and inflammatory cytokines such as TNFa, IL-12, and IFN $\gamma[3,4]$.

Fatty acids have been shown to alter the oxidative environment of cellular lipids [5] and, by doing so, potentially affect macrophage functions [6]. Fatty acid-binding proteins (FABPs) are a family of small, highly conserved, cytoplasmic proteins that bind long chain fatty acids and other hydrophobic ligands, and are involved in fatty acid uptake, transport, and metabolism [7]. FABP5, the epidermal fatty acid-binding protein [8], has been shown to

Dr. Fabienne Gally

Department of Biomedical Research, National Jewish Health

1400 Jackson Street, Room K827

Denver, CO 80206 (USA)

E-Mail gallyf@ njhealth.org 
be upregulated in alveolar macrophages during acute lung rejection [9]. We have previously demonstrated an unknown contribution of FABP5 to Influenza A virus pathogenesis, where it controls excessive oxidative damage and inflammation [10]. Recently, however, FABP5 has been shown to limit the anti-inflammatory response in murine macrophages following intraperitoneal lipopolysaccharide (LPS) treatment [11]. This apparent contradiction prompted us to identify the role of FABP5 in the outcome of L. monocytogenes infection and to explore the immune response elicited by this intracellular pathogen in FABP5-deficient macrophages. Here, we clearly demonstrate that FABP5 increases susceptibility to L. monocytogenes infection as $\mathrm{FABP}^{-/-}$animals exhibited heightened resistance to bacterial infection, whereas increased mortality and bacterial burden were observed in mice overexpressing FABP5 in their myeloid cells.

\section{Materials and Methods}

Construction of the Rosa26-STOPflox-Fabp5-2A-YFP Mouse

Rosa26-STOPflox-Fabp5-2A-YFP mice were generated by the Mouse Genetics Core Facility at National Jewish Health. In these mice, the ROSA26 locus contains a STOP-flox cassette upstream of mouse Fabp 5 cDNA linked by a $2 \mathrm{~A}$ peptide to YFP. Upon exposure to Cre recombinase (LysM-Cre), the stop cassette is deleted and the Fabp5-2A-YFP transcript undergoes cotranslational cleavage due to the $2 \mathrm{~A}$ peptide, generating 2 separate Fabp5 and YFP proteins in myeloid cells.

Briefly, the targeting construct was made in a pBSKS-DTA vector. The Rosa26 genomic regions were isolated from BAC clone RP23-324O18, mouse Fabp5 was amplified from a plasmid containing its cDNA (clone ID 301376900, Dharmacon), the STOP flox cassette (containing a positive selection marker Neo flanked by loxP sequences) was cloned from pBigT (Addgene, $\# 21270$ ), and the $2 \mathrm{~A}$ peptide was synthesized in the primers to amplify YFP. The linearized construct was electroporated into JM8.A3 cells and cells were selected with G418 (positive selection) for targeted insertion of the construct. Selected clones were picked and frozen. Successfully targeted homologous recombinant clones were determined by screening for the loss of the Rosa 26 allele by qPCR, followed by PCR using a primer pair nested in Rosa26 and YFP [12]. Functionality of the construct in the ROSA26 locus was verified on homologous recombinant embryonic stem (ES) cell clones by expansion and electroporation of these clones with a plasmid expressing Cre recombinase expression under the control of the CMV promoter. Four days after electroporation, these ES cell clones were analyzed by flow cytometry to assess the expression of YFP in the absence or presence of Cre recombinase. Two clones were selected following chromosome counting for injection into C57BL/6J blastocysts, which were transferred into pseudopregnant ICR females. Chimeric offspring were bred for germline transmission, and germline transmission was achieved for both clones.
Animals

$\mathrm{FABP}^{-/-}$mice and littermate wild-type (WT) controls, on a C57BL/6J background, were kindly provided by Dr. Gokhan Hotamisligil at Harvard University (Boston, MA, USA), and bred in our Biological Resources Center, along with the transgenic mice described above. Mice were kept on a 12-h light-dark cycle with ad libido access to food and water.

\section{L. monocytogenes and Mouse Infection}

The WT virulent strain 10403 S of $L$. monocytogenes was used for all animal studies. Mice were injected i.v. with $200 \mu \mathrm{L}$ of $L$. monocytogenes diluted in PBS. The actual L. monocytogenes infectivity dose was determined by plating the injection input on TSB agar plates. Liver and spleen bacterial burden were determined by homogenization in $0.1 \%$ Nonidet P-40 (USB) using a T25 digital Ultra Turrax tissue grinder (IKA Works), and lysed at room temperature for $30 \mathrm{~min}$. Serial dilutions of homogenates were plated onto TSB agar plates and counted after overnight incubation at $37^{\circ} \mathrm{C}$. To determine survival, mice were monitored every $12 \mathrm{~h}$ postinfection for signs of morbidity.

\section{Alanine Aminotransferase Assay}

Serum alanine aminotransferase (ALT) was measured using an ALT colorimetric reagent kit (Teco Diagnostics) and adapted to a 96-well plate format. Briefly, $10 \mu \mathrm{L}$ of fresh serum was placed in each well and incubated at $37^{\circ} \mathrm{C}$ for 30 min with $50 \mu \mathrm{L}$ ALT substrate, 10 min with $50 \mu \mathrm{L}$ color reagent, and 5 min with $200 \mu \mathrm{L}$ color developer in accordance with the manufacturer's instructions. Absorbance was measured at $505 \mathrm{~nm}$ using a SynergyHT plate reader with Gen 5 software (BioTek) and the serum ALT concentrations were determined using a standard curve of serially diluted ALT calibrator.

\section{Liver Histological Evaluation}

Whole livers were removed from naïve or infected mice, fixed in $10 \%$ buffered formalin, paraffin-embedded, and stained with hematoxylin and eosin. Color images of liver sections were acquired on a Nikon Eclipse 80i microscope equipped with a Nikon DS-U/L2-Ri1 camera using NIS-Elements AR software.

\section{Intracellular Inducible Nitric Oxide Synthase Determination}

All staining procedures were done in PBS supplemented with $0.1 \%$ BSA and $0.05 \%$ sodium azide at $4{ }^{\circ} \mathrm{C}$. Single-cell suspensions from spleens were prepared by mechanical disruption using 100 $\mu \mathrm{m}$ nylon mesh (Fisherbrand). After red blood cell lysis with ACK buffer, cells were counted using trypan blue exclusion, and stained using the following antibodies: CD3e-APC (145-2C11), CD8APC (53-6.7), CD4-APC (L3T4), NK1.1-APC (PK136), CD19APC (MB19-1), CD11b-Pacific Blue (M1/70), CD11c-APC Cy7 (N418) and Ly6G PerCP (1A8) from eBiosciences; and Ly6C-FITC (AL-21) from BD Pharmingen. Intracellular inducible nitric oxide synthase (iNOS) proteins were detected using NOS2-PE (CXNFT, eBiosciences). To identify iNOS-producing monocytes, we first gated on live cells and excluded doublets, lymphocytes $\mathrm{APC}^{+}$cells, and $\mathrm{Ly}_{6 \mathrm{G}}{ }^{+}$neutrophils. Second, we gated on $\mathrm{CD} 11 \mathrm{~b}^{+} / \mathrm{Ly}_{6} \mathrm{C}^{+}$ monocytes expressing iNOS. For the detection of intracellular iNOS, the BD Cytofix/Cytoperm plus kit (BD BioSciences) was used according to the manufacturer's instructions. Samples were acquired using a $\mathrm{CyAn}^{\mathrm{TM}}$ Flow Cytometer (Dako) and data were analyzed using FlowJo v10.2 software (Tree Star, Inc.). 
Cytokine Determination

Serum was separated by centrifugation using Z-Gel microtubes (Sarstedt). Cytokine concentrations in mouse serum were measured using the MSD Mouse Th1/Th2 9-plex ultrasensitive kit (Meso Scale Discovery, Gaithersburg, MD, USA) per manufacturer's instructions.

\section{Bone Marrow-Derived Macrophages}

Bone marrow-derived macrophages (BMDMs) were generated in vitro by flushing bone marrow from mouse tibias and femurs. Progenitor cell suspensions were cultured for 5 days in DMEM containing 10\% FBS, $100 \mathrm{U} / \mathrm{mL}$ penicillin, $100 \mu \mathrm{g} / \mathrm{mL}$ streptomycin, and 10\% L929 cell-conditioned medium as a source of CSF-1. Macrophage differentiation was confirmed by flow cytometry (>95\% positive for $\mathrm{F} 4 / 80$ and $\mathrm{CD} 11 \mathrm{~b}$ ).

\section{Griess Reaction}

Nitrate anion $\left(\mathrm{NO}_{2}^{-}\right)$production by BMDM was measured using the Griess reagent system (Promega, Madison, WI, USA) following the manufacturer's instructions. Briefly, cells were stimulated with recombinant mouse TNFa (10 ng/mL; eBiosciences), mouse IFN $\gamma$ (10 U/mL; eBiosciences), or LPS (100 ng/mL; Sigma) diluted in BMDM media, and added alone or in combination to adherent BMDM cultures for up to $48 \mathrm{~h}$. Fifty microliters of supernatant was used to determine the micromolar amount of nitrite by measuring the absorbance at $540 \mathrm{~nm}$ using a SynergyHT plate reader with Gen5 software (Bio-Tek).

\section{Macrophage Listeria-Killing Assay}

Exponential-phase L. monocytogenes (10403S) was added to BMDM at a multiplicity of infection (MOI) of 10 , incubated for $30 \mathrm{~min}$ at $37^{\circ} \mathrm{C}$ to allow phagocytosis, removed, and replaced with antibiotic-free media for another $30 \mathrm{~min}$ at $37^{\circ} \mathrm{C}$ to complete bacterial uptake. Gentamycin $(200 \mu \mathrm{g} / \mathrm{mL}$; Sigma $)$ was added to kill any remaining extracellular bacteria so that only intracellular bacteria were measured. Colony-forming units were determined by plating serial dilutions of lysates on TSB agar plates after overnight incubation at $37^{\circ} \mathrm{C}$.

\section{Bone Marrow Chimeras}

Bone marrow cells were flushed from the femurs and tibias of donor mice. Red blood cells were lysed with ACK buffer (Quality Biological, Inc.) and washed twice and resuspended in PBS. Recipient mice were irradiated with $900 \mathrm{rad}$ and received a total of $5 \times 10^{6}$ bone marrow cells through tail vein injection. Mice were allowed to recover for 8 weeks before being used in experiments.

\section{Statistical Analysis}

All data are expressed as means \pm SEM. Statistical significance was evaluated using Prism 5 for Mac OS X software to perform Student's $t$ test (unpaired, two-tailed) for comparisons between 2 groups. One-way analysis of variance was used for multiple comparisons, and Tukey's post hoc test was applied where appropriate. For Kaplan-Meier survival data, median survival times and significance were compared between groups using a log-rank (Mantel-Cox) test.

\section{Results}

FABP5-Deficient Mice Are Resistant to Lethal Listeria Infection

A recent study reported that LPS injury of $\mathrm{FABP} 5^{-/-}$ mice resulted in less liver injury despite increased macrophage infiltration [11]. Thus, we hypothesized that $\mathrm{FABP}^{-/-}$mice may be protected against bacteria-induced liver injury. To test this hypothesis, WT and $\mathrm{FABP}^{-/-}$mice were injected i.v. with a lethal dose of $L$. monocytogenes. Confirming our hypothesis, $\mathrm{FABP} 5^{-/-}$ mice survived a dose of $1.7 \times 10^{5} \mathrm{CFUs}$ and showed no outward signs of illness (Fig. 1a), while half of the WT mice succumbed to L. monocytogenes infection. In addition, $\mathrm{FABP}^{-/-}$mice experienced less weight loss during infection in comparison to WT mice (Fig. 1b). Next, we examined the bacterial load in the liver and spleen $48 \mathrm{~h}$ after infection, and found it reduced in $\mathrm{FABP}^{-/-}$mouse organs (Fig. 1c). We assessed liver damage by not only measuring serum levels of ALT (Fig. 1d), but also by quantifying infiltrations of inflammatory cells in the whole liver (Fig. 1e, f). While the ALT levels were not significantly different between $\mathrm{WT}$ and $\mathrm{FABP} 5^{-/-}$mice, WT mice had more inflammatory infiltrates in the liver than $\mathrm{FABP}^{-/-}$mice.

\section{FABP5-Deficient Mice Have Diminished Listeria- \\ Induced Cytokine Production}

The transactivation of macrophage bactericidal activity and survival to L. monocytogenes infection requires IL12-dependent production of IFN $\gamma$ by $\mathrm{NK}$ and $\mathrm{CD} 8^{+} \mathrm{T}$ cells in an antigen-independent manner $[13,14]$. Thus, we quantified the level of IFN $\gamma$ and IL-12p70 in the serum following infection. Both IFN $\gamma$ (Fig. 2a) and IL12 p70 (Fig. 2b) were reduced by $50 \%$ in $\mathrm{FABP}^{-/-}$mice compared to WT mice. Similarly, other inflammatory cytokines were significantly reduced in the serum of $\mathrm{FABP}^{-/-}$mice, including IL-1 $\beta$ (Fig. 2c), IL-6 (Fig. 2d), KC (Fig. 2e), and TNFa (Fig. 2f). Furthermore, we measured the level of anti-inflammatory cytokine IL-10 (Fig. $2 \mathrm{~h}$ ) and showed that it was also significantly reduced in $\mathrm{FABP}^{-/-}$mice. Together, these data suggest that FABP5 deficiency in mice results in a lower L. monocytogenes burden and reduced tissue damage, as well as dampened inflammatory responses.

\section{FABP5-Deficient Macrophages Are Better Producers of $R O S$}

Macrophages are central to the control of L. monocytogenes infection and replication via the inhibition of vac- 

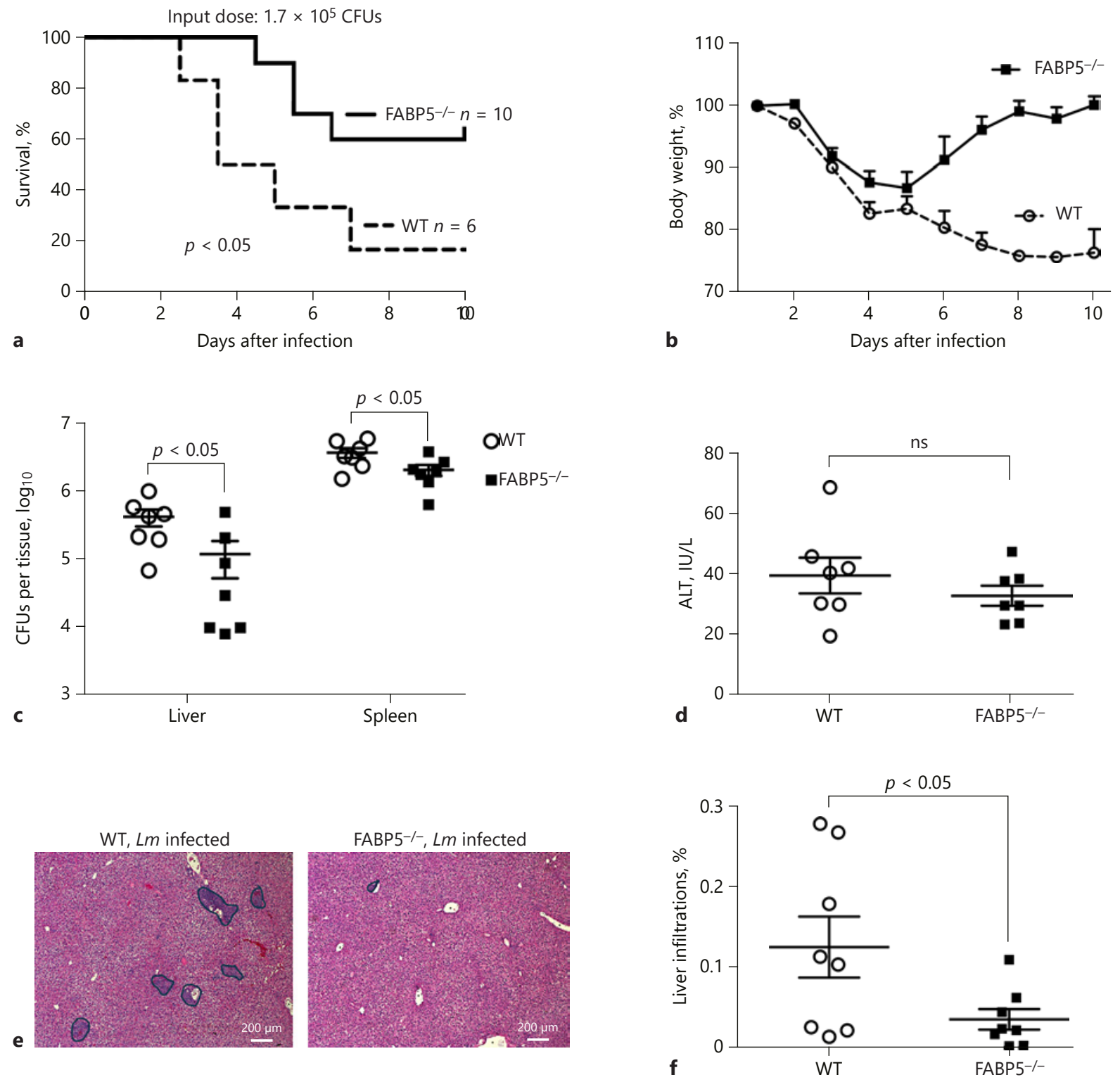

Fig. 1. Enhanced resistance of $\mathrm{FABP} 5^{-/-}$mice to lethal infection with L. monocytogenes. a Kaplan-Meier survival plot of mice i.v. infected with L. monocytogenes. Six WT (dashed line) and 10 $\mathrm{FABP}^{-1-}$ (continuous line) mice were infected with $1.7 \times 10^{5}$ CFUs. b Changes in body weight loss following infection from mice described in a. c L. monocytogenes burden in the liver and spleen of WT (open circles) and FABP5 $5^{-/}$(black squares) mice $48 \mathrm{~h}$ postinfection ( 7 mice per group) infected with $2.4 \times 10^{4}$ CFUs. d Serum was collected from the same WT (open circles) and $\mathrm{FABP}^{-1-}$ (black squares) mice described in c and ALT was quantified using a modified Reitman-Frankel colorimetric end-point reaction. e Stained WT and $\mathrm{FABP}^{-/-}$livers $48 \mathrm{~h}$ after L. monocytogenes $(\mathrm{Lm})$ infection. Cellular infiltrates are surrounded by black lines. HE. $\times 20$. f Quantification of cellular infiltrates in WT (open circles) and $\mathrm{FABP}^{-/-}$(black squares) livers (8 mice per group). Data are representative of 4 independent experiments. 


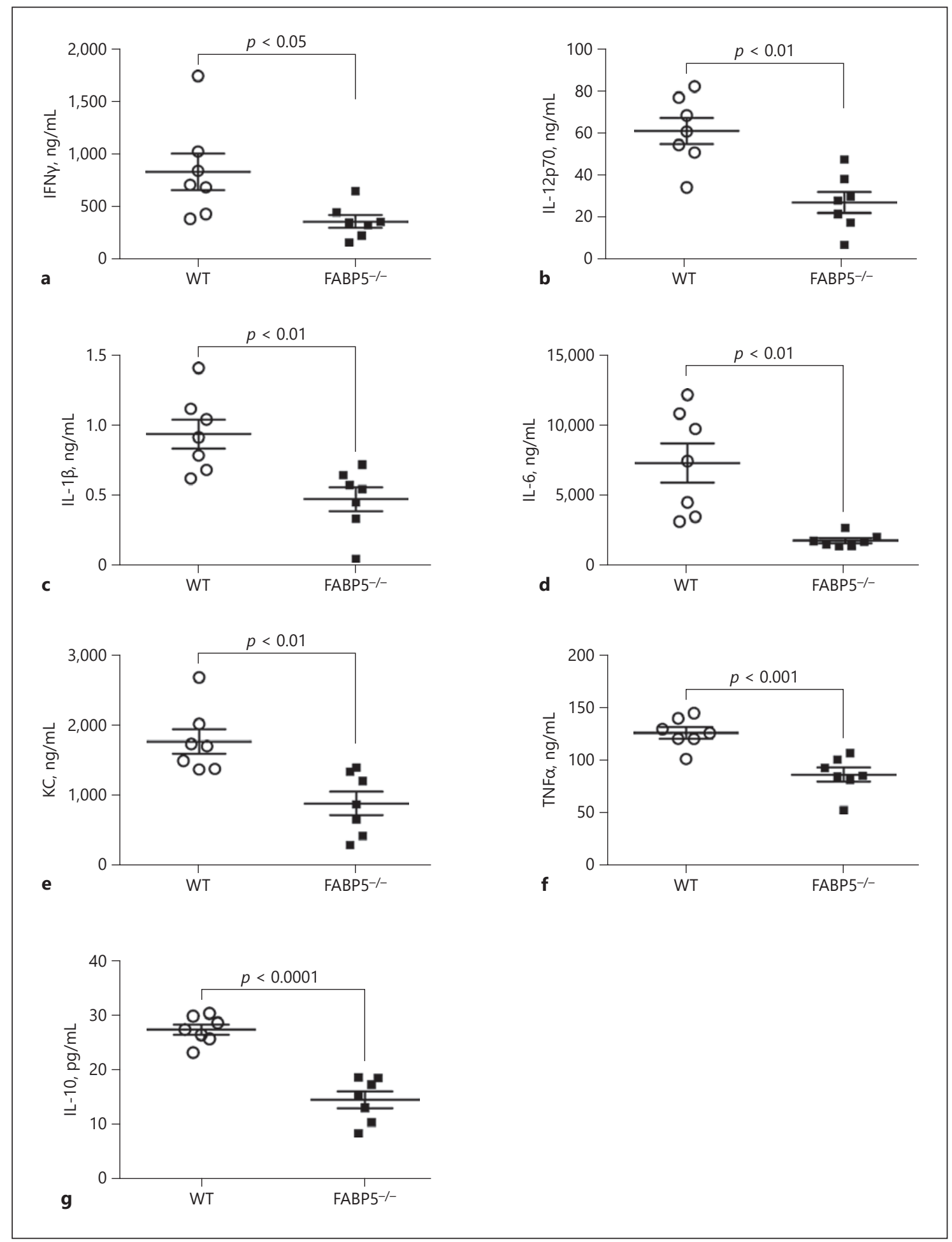

Fig. 2. Decreased levels of multiple cytokines in L. monocytogenesinfected $\mathrm{FABP}^{-/-}$mice in comparison to WT mice. a IFN $\gamma$. b IL12p70. c IL-1 $\beta$. d IL-6. e KC. f TNFa. g IL-10. Cytokines were measured in the serum of WT (open circles) or $\mathrm{FABP}^{-/-}$(black squares) mice infected with $4.5 \times 10^{4} \mathrm{CFUs} 48 \mathrm{~h}$ postinfection using the multiplex MSD plate ( $n=7$ mice/group). Data are representative of 4 independent experiments. 


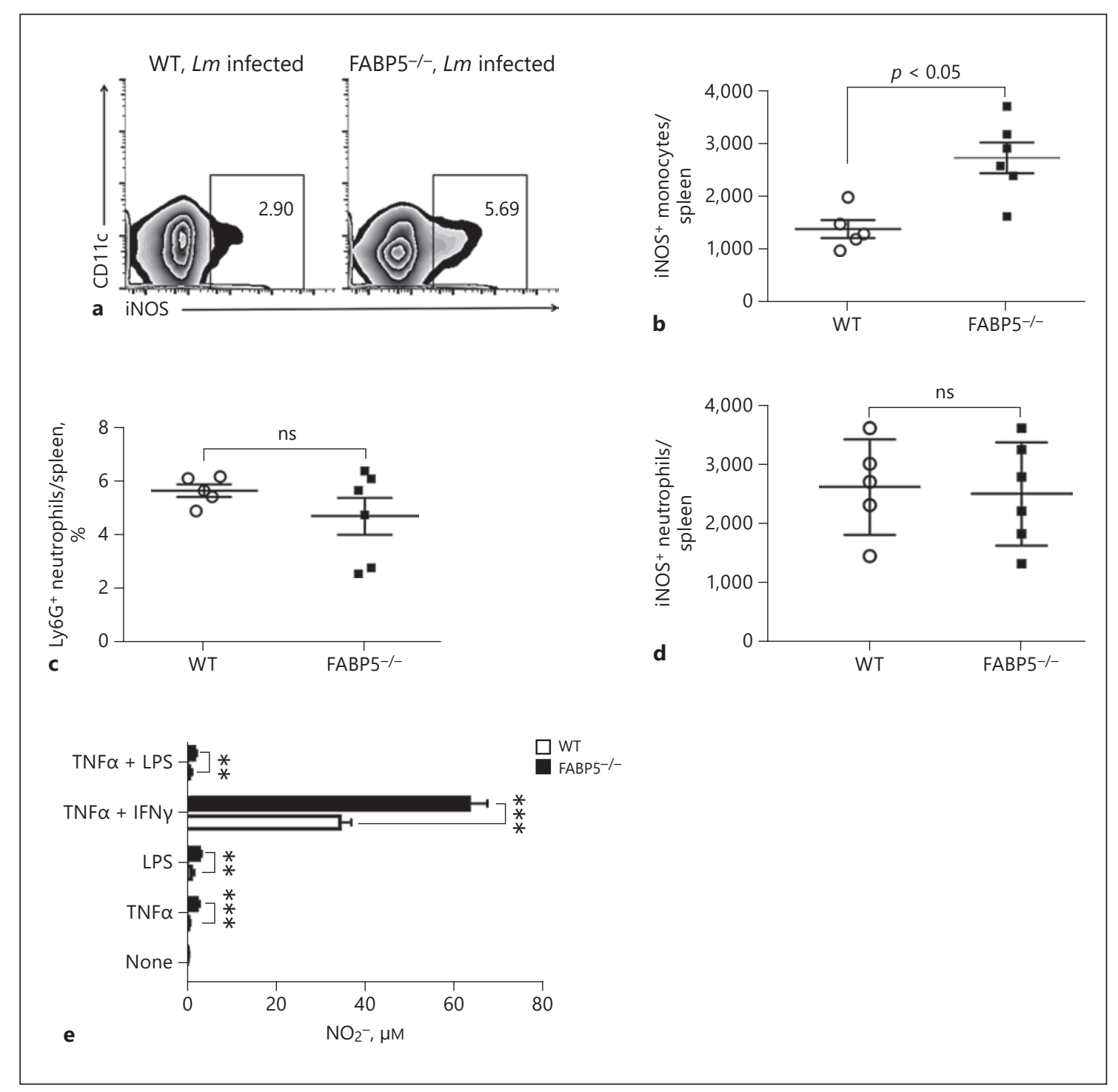

Fig. 3. Increased in vivo iNOS activation by $\mathrm{Ly}_{6 \mathrm{C}} \mathrm{C}^{+}$monocytes in $\mathrm{FABP}^{-/-}$mice and increased in vitro $\mathrm{NO}_{2}^{-}$production by $\mathrm{FABP}^{-1-}$ macrophages. a Representative density plots of iNOS expression in $\mathrm{CD}_{11} \mathrm{~b}^{+} / \mathrm{Ly}_{6 \mathrm{G}} / \mathrm{Ly}_{6} \mathrm{C}^{+}$gated spleen monocytes $(n=5-6$ mice/group) Lm, L. monocytogenes. b Absolute numbers of iNOS ${ }^{+}$ monocytes in WT (open circles) and $\mathrm{FABP}^{-/-}$(black squares) spleen $48 \mathrm{~h}$ postinfection ( $n=5-6$ mice/group). c Proportion of neutrophils $\left(\mathrm{Ly}_{6 \mathrm{G}}{ }^{+}\right)$in WT (open circles) and $\mathrm{FABP}^{-/-}$(black squares) spleen $48 \mathrm{~h}$ postinfection ( $n=5-6$ mice/group). d Abso- lute numbers of iNOS $^{+}$neutrophils in WT (open circles) and $\mathrm{FABP}^{-/-}$(black squares) spleen $48 \mathrm{~h}$ postinfection $(n=5-6 \mathrm{mice} /$ group). e FABP5 ${ }^{-1-} \mathrm{BMDMs}$ secrete more $\mathrm{NO}_{2}{ }^{-}$than WT BMDMs in response to inflammatory stimuli. WT and $\mathrm{FABP}^{-/-} \mathrm{BMDMs}$ were left untreated or stimulated with $10 \mathrm{ng} / \mathrm{mL} \mathrm{TNFa}, 100 \mathrm{ng} / \mathrm{mL}$ LPS, and $10 \mathrm{U} / \mathrm{mL}$ IFN $\gamma$ in combination as indicated. Supernatants were obtained $24 \mathrm{~h}$ after stimulation and $\mathrm{NO}_{2}^{-}$production was measured by Griess reaction. Bars represent mean nitrite $\left(\mathrm{NO}_{2}{ }^{-}\right.$, $\mu \mathrm{M}) \pm$ SEM. Data are representative of 3 independent experiments. uole and cell-to-cell escape of the bacterium. Therefore, we hypothesized that the resistance of $\mathrm{FABP}^{-/-}$mice to L. monocytogenes may be due to more efficient macrophage activation in the absence of FABP5. To test this hypothesis, we analyzed the intracellular expression of iNOS in splenic monocytes by flow cytometry (Fig. 3a) and observed twice as many iNOS ${ }^{+}$monocytes in the $\mathrm{FABP}^{-/-}$spleens when compared to WT mice (Fig. 3b). In contrast, neutrophil numbers and iNOS-producing neutrophils, assessed by flow cytometry, were not significantly different between WT and FABP $5^{-1-}$ mice (Fig. 3c, d). To understand whether $\mathrm{FABP}^{-/-}$macrophages have 


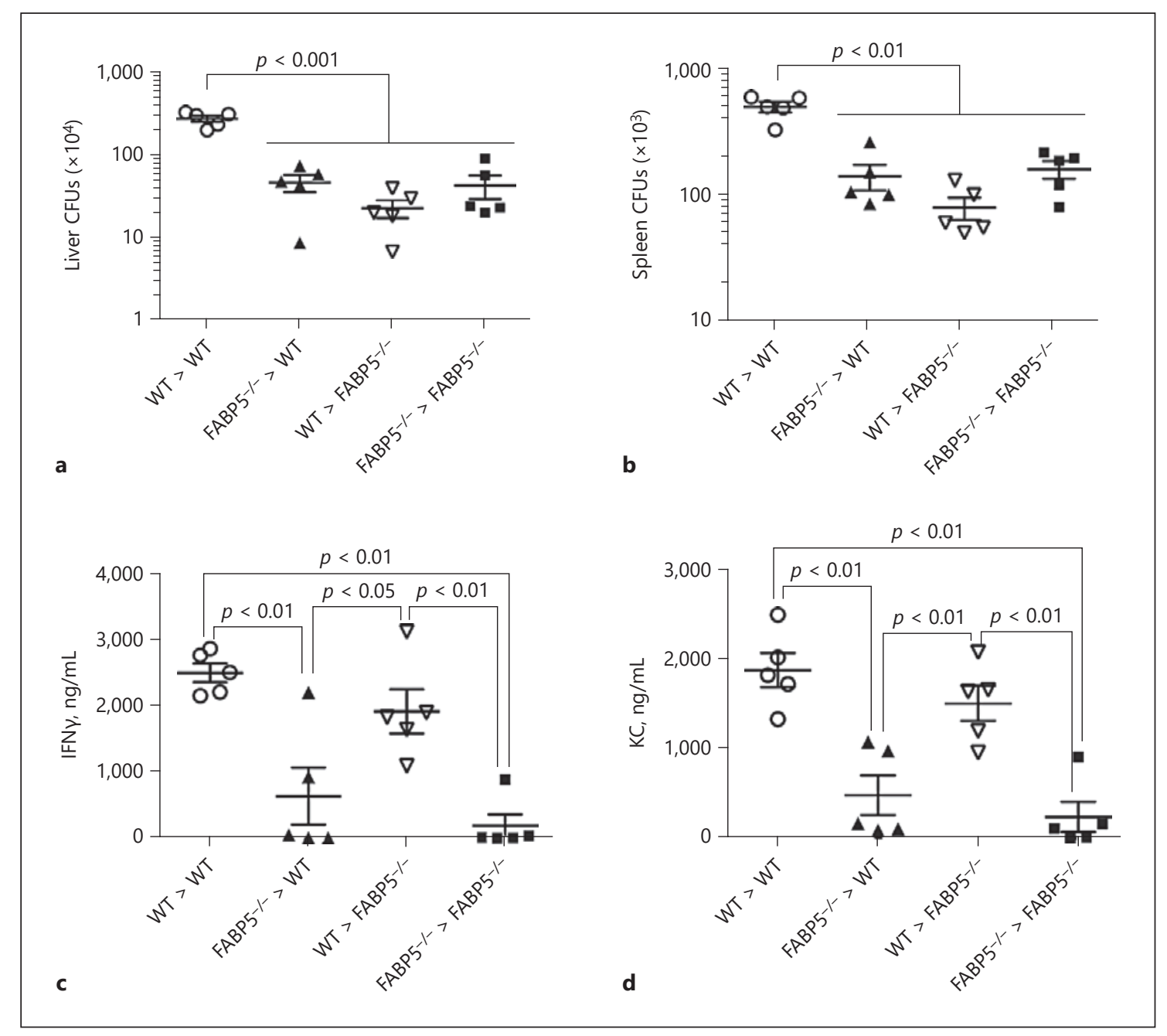

Fig. 4. Bone marrow chimeras confirm the resistance to L. monocytogenes infection in $\mathrm{FABP} 5^{-/-}$mice. L. monocytoges burden in the liver (a) and spleen (b) of bone marrow chimeric mice $48 \mathrm{~h}$ postinfection ( 5 mice per group) infected with $3.8 \times 10^{4}$ L. monocytogenes. IFN $\gamma(\mathbf{c})$ and $\mathrm{KC}(\mathbf{d})$ were measured in the serum of bone marrow chimeric mice infected with $3.8 \times 10^{4}$ CFUs $48 \mathrm{~h}$ postinfection using the multiplex MSD plate. Data are representative of 2 independent experiments.

enhanced activation, we measured the secretion of $\mathrm{NO}_{2}{ }^{-}$ by BMDMs in response to inflammatory stimuli. LPS alone, or in combination with TNFa, resulted in significantly increased levels of $\mathrm{NO}_{2}^{-}$in the supernatant of $\mathrm{FABP}^{-/-}$BMDM compared to WT BMDM (Fig. 3e).

\section{FABP5 Deficiency in the Hematopoietic}

Compartment Confers Resistance to Listeria

Infection-Induced Inflammation

To test whether FABP5-deficient hematopoietic cells are responsible for resistance to $L$. monocytogenes infection, we created bone marrow chimeric mice, using $\mathrm{WT}$ and $\mathrm{FABP}^{-/-}$irradiated mice as both recipients and donors. The following chimeras were generated: WT recipient with WT bone marrow (WT $>\mathrm{WT}$ ), WT recipient with $\mathrm{FABP}^{-/-}$bone marrow $\left(\mathrm{FABP}^{-/-}>\right.$ $\mathrm{WT}$ ), $\mathrm{FABP}^{-/-}$recipient with $\mathrm{WT}$ bone marrow (WT > $\mathrm{FABP}^{-/-}$), and $\mathrm{FABP}^{-/-}$recipient with $\mathrm{FABP}^{-/-}$bone marrow $\left(\mathrm{FABP}^{-/-}>\mathrm{FABP}^{-/-}\right.$). Eight weeks after radiation and bone marrow reconstitution, recipient mice were infected with $L$. monocytogenes, and tissues were harvested $48 \mathrm{~h}$ postinfection. As shown in Figure 4(a, b), any mouse that already had or received FABP5-deficient immune cells had a lower bacterial burden. However, mice that received $\mathrm{FABP}^{-/-}$bone marrow had lower inflammatory cytokines (e.g., IFN $\gamma$ and KC) (Fig. 4c, d). 


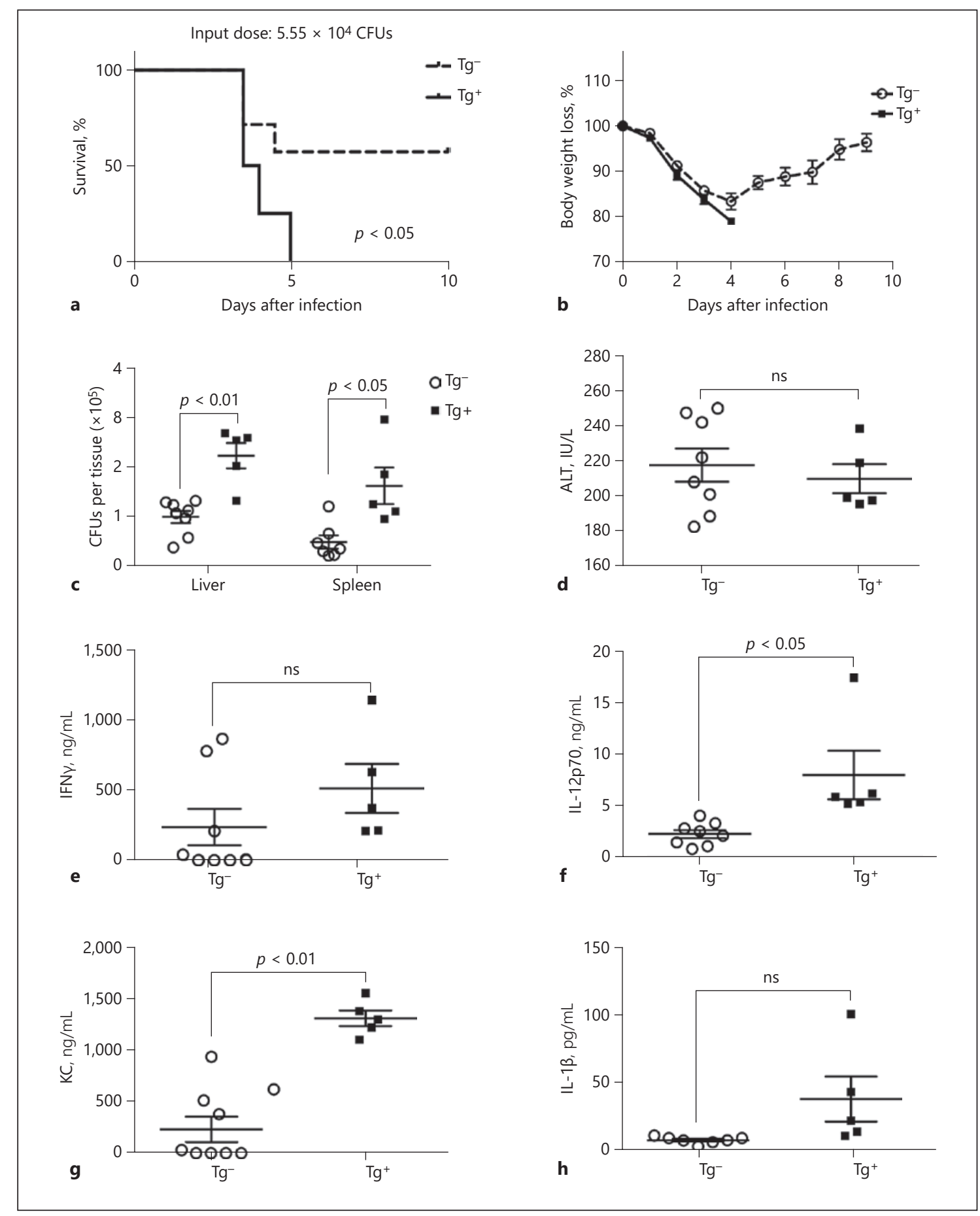

Fig. 5. Increased susceptibility of myeloid cell-specific FABP5 transgenic mice to lethal infection with $L$. monocytogenes. a Kaplan-Meier survival plot of mice i.v. infected with L. monocytogenes. Five LysM-FABP5-Tg- (continuous line) and 7 LysM-FABP5-Tg ${ }^{+}$ (dashed line) mice were infected with $5.55 \times 10^{4} \mathrm{CFUs}$. b Changes in body weight loss following infection from mice described in $\mathbf{a}$. c L. monocytogenes burden in liver and spleen of LysM-FABP5-Tg(open circles) and LysM-FABP5-Tg ${ }^{+}$(black squares) mice $48 \mathrm{~h}$ postinfection (5-8 mice per group) infected with $4.2 \times 10^{4}$
L. monocytogenes. d Serum was collected from the same LysMFABP5-Tg- (open circles) and LysM-FABP5- $\mathrm{Tg}^{+}$(black squares) mice as described in c and ALT was quantified using a modified Reitman-Frankel colorimetric end-point reaction. e IFN $\gamma$. f IL12p70. g KC. h IL-1 $\beta$. Cytokines were measured in the serum of LysM-FABP5-Tg- (open circles) or LysM-FABP5-Tg ${ }^{+}$(black squares) mice infected with $4.2 \times 10^{4} \mathrm{Lm} 48 \mathrm{~h}$ postinfection using the multiplex MSD plate. Data are representative of 3 independent experiments. 


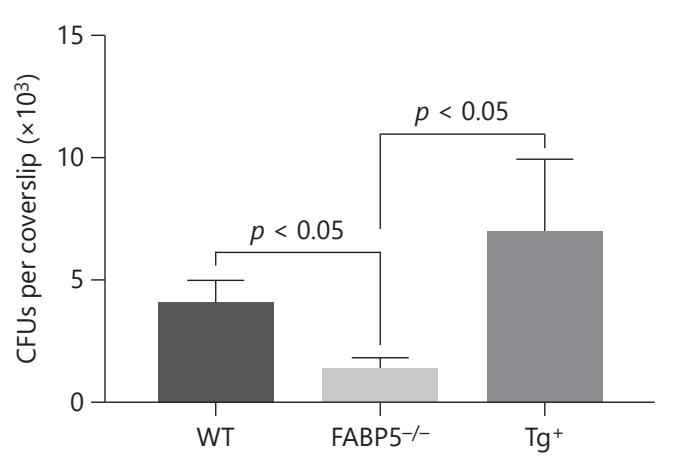

Fig. 6. $\mathrm{FABP}^{-1-}$ bone marrow-derived macrophages (BMDMs) have increased bactericidal activity and kill intracellular L. monocytogenes more efficiently than WT or LysM-FABP5- $\mathrm{Tg}^{+}$cells. BMDMs from WT, FABP5 ${ }^{-/}$, and LysM-FABP5- $\mathrm{Tg}^{+}$mice were plated on glass coverslips ( $n=3$ per group), allowed to adhere, and treated with $100 \mathrm{ng} / \mathrm{mL}$ LPS $\pm 10 \mathrm{U} / \mathrm{mL}$ IFN $\gamma$ for $18 \mathrm{~h}$. Cells were infected for $4 \mathrm{~h}$ with $L$. monocytogenes at a $\mathrm{MOI}=10$ and the coverslips were lysed for enumeration of the bacterial load by plating serial dilutions of lysate. Bars represent mean intracellular $L$. monocytogenes CFUs \pm SEM from 1 of 3 independent experiments.

These data suggest that FABP5 deficiency in immune cells confers heightened protection from L. monocytogenes infection. In addition, because tissue-resident macrophages are radio-resistant, they might still be present in irradiated $\mathrm{FABP}^{-1-}$ recipient mice, thus explaining the protection in $\mathrm{WT}>\mathrm{FABP}^{-/-}$chimeric mice.

\section{Myeloid Cell-Specific FABP5 Overexpression Further}

Confirms the Importance of FABP5 Deficency in

Macrophages for Resistance to Listeria Infection

To test whether $\mathrm{FABP}^{-/-}$myeloid cells are responsible for the resistance to L. monocytogenes infection, we generated myeloid cell-specific FABP5-overexpressing mice by crossing LysM-Cre mice with mice carrying Rosa26STOPflox-Fabp5-2A-YFP (FABP5-Tg) (online suppl. Fig. S1a, b; see www.karger.com/doi/10.1159/000496405 for all online suppl. material). We then challenged LysMFABP5- $\mathrm{Tg}^{+}$and LysM-FABP5-Tg- mice with a lethal dose of L. monocytogenes. LysM-FABP5- $\mathrm{Tg}^{+}$mice exhibited worse survival than LysM-FABP5-Tg- mice (Fig. 5a), indicating that overexpression of FABP5 in the myeloid cells decreases the innate immune defense against $L$. monocytogenes infection. Of note, we did not see any difference in weight loss between LysM-FABP5- $\mathrm{Tg}^{+}$and LysM-FABP5- $\mathrm{Tg}^{-}$mice during infection (Fig. 5b).
Next, we examined the bacterial load in the liver and spleen $48 \mathrm{~h}$ after infection and found increased bacterial load in LysM-FABP5- $\mathrm{Tg}^{+}$mouse organs compared to in LysM-FABP5-Tg- mice (Fig. 5c). We assessed liver damage by measuring serum levels of ALT but saw no difference between LysM-FABP5-Tg ${ }^{+}$and LysM-FABP5-Tgmice (Fig. 5d). We also quantified the level of IFN $\gamma$ and IL-12p70 in the serum following infection. Both IFN $\gamma$ (Fig. 5e) and IL-12p70 (Fig. 5f) were increased in LysMFABP5- $\mathrm{Tg}^{+}$mice compared to in LysM-FABP5- $\mathrm{Tg}^{-}$mice. Similarly, other inflammatory cytokines were significantly increased in the serum of LysM-FABP5- $\mathrm{Tg}^{+}$mice, including KC (Fig. 5g), and IL-1 $\beta$ (Fig. 5h). Together, these data suggest that FABP5 overexpression in myeloid cells contributes to a higher bacterial burden and increased inflammatory response.

\section{Increased Bactericidal Activity of FABP5-Deficient Macrophages}

To demonstrate whether FABP5 expression decreases the bactericidal activity of macrophages, we examined macrophage killing abilities in vitro using BMDMs of $\mathrm{WT}, \mathrm{FABP}^{-/-}$, and LysM-FABP5- $\mathrm{Tg}^{+}$mice. We found that cultured $\mathrm{FABP}^{-/-} \mathrm{BMDM}$ have an increased ability to kill intracellular L. monocytogenes compared to WT or LysM-FABP5-Tg ${ }^{+}$cells (Fig. 6). Together, our data show that in comparison to WT mice, FABP5 $5^{-/}$mice exhibit significantly elevated monocyte/macrophage activation in response to L. monocytogenes infection in vitro, likely resulting in improved protection against L. monocytogenes infection in vivo.

\section{Discussion}

Myeloid cells orchestrate the innate immune response against $L$. monocytogenes bacterial infection [15]. As previous data showed that FABP5 deletion attenuated LPSinduced hepatic injury [11], we hypothesized that FABP5 expression would limit the early innate immune response of myeloid cells in response to L. monocytogenes infection. Here, we showed that $\mathrm{FABP}^{-/-}$mice have improved viability compared to WT mice, as well as a decreased bacterial burden in the liver and spleen, and reduced hepatic inflammation, revealing a previously unknown key role of FABP5 in controlling the innate immune response to $L$. monocytogenes infection, specifically in myeloid cells.

Previous studies have shown that the inflammatory cytokines IFN $\gamma[16,17]$, TNFa $[18,19]$, and IL-6 [20] play an important role in the host's resistance to L. monocyto- 
genes infection, and that the peak of these cytokines in the bloodstream corresponds with the highest bacterial titers [21]. However, these cytokines did not appear to play an active role in lethality from infection with a high dose of L. monocytogenes [22]. Our observations of reduced bacterial burden and reduced inflammation in $\mathrm{FABP}^{-/-}$mice correlate with decreased systemic levels of cytokines that are usually induced by L. monocytogenes invasion $[23,24]$. Deficiency of the anti-inflammatory cytokine IL-10 has been shown to improve resistance to L. monocytogenes infection $[25,26]$, yet it is also required for memory $\mathrm{T}$ cells [27]. Since IL-10 was reduced in $\mathrm{FABP} 5^{-/-}$mice compared to WT mice, it would be intriguing to determine whether $\mathrm{FABP}^{-/-}$mice have an increased sensitivity to a secondary L. monocytogenes infection, given that FABP5 has been shown to be essential for the maintenance, longevity, and function of tissue-resident memory T cells [28].

We also showed that FABP5-deficient inflammatory macrophages had increased amounts of iNOS while FABP5-deficient BMDMs produced higher amounts of $\mathrm{NO}_{2}{ }^{-}$when stimulated with TNF $\alpha$, IFN $\gamma$, or LPS. This suggests that FABP5-deficient macrophages are better equipped at killing L. monocytogenes than their WT counterparts. As neutrophils are the most potent ROS producers, we also considered that they might play a role in bacterial killing. However, FABP 5 is poorly expressed in neutrophils, and we did not see a difference in neutrophils proportions or in $\mathrm{iNOS}^{+}$neutrophil numbers between $\mathrm{WT}$ and $\mathrm{FABP}^{-/-}$mice.

To test whether FABP5-deficient immune cells, in particular macrophages, confer resistance to L. monocytogenes infection, we generated bone marrow chimeric mice. Interestingly, any chimera that already had or received FABP5-deficient cells showed a lower bacterial burden. This result corroborated our hypothesis that FABP5-deficient macrophages decrease the L. monocytogenes bacterial burden, since tissue-resident macrophages are known to be resistant to radiation $[29,30]$, and thus would still be present in the irradiated recipient mouse. Of note, the cytokines in the bloodstream of the chimeric mice followed the phenotype of the bone marrow donor. We found that WT recipients that received FABP5-deficient bone marrow $\left(\mathrm{FABP}^{-/-}>\mathrm{WT}\right.$ ) had similar levels of cytokines than $\mathrm{FABP}^{-/-}>\mathrm{FABP}^{-/-}$mice, while FABP5deficient recipient that received $\mathrm{WT}$ bone marrow (WT $>\mathrm{FABP}^{-{ }^{-}}$) had cytokine levels comparable to WT $>\mathrm{WT}$ mice. This could be due to the fact that, in the mouse liver, 2 different subsets of $\mathrm{F} 4 / 80^{+}$macrophages have been identified: the radio-resistant resident $\mathrm{CD}^{+} 8^{+}$subset (Kupffer cell) and the radio-sensitive recruited $\mathrm{CD} 11 \mathrm{~b}^{+}$ subset. The $\mathrm{CD} 11 \mathrm{~b}^{+}$subset, which is involved in antitumor immunity and cytokine production $[31,32]$, is derived from bone marrow and originates from the donor mouse while the radio-resistant Kupffer cells, which produce ROS and have bactericidal activity, are resident cells from the recipient mouse, explaining the cytokine results obtained with our bone marrow chimeric animals.

We then created transgenic mice that overexpressed FABP 5 specifically in myeloid cells by crossing them with LysM-Cre mice, and we found that overexpression of FABP5 decreased survival and increased bacterial burden and inflammation, suggesting that FABP5 overexpression in myeloid cells increases the L. monocytogenes burden and subsequent inflammation. Finally, using an in vitro assay, we found that FABP5-deficient macrophages were more efficient at killing L. monocytogenes than WT or LysM-FABP5- $\mathrm{Tg}^{+}$macrophages.

Previously, we showed that $\mathrm{FABP}^{-/-}$mice have increased viral-induced lung inflammation compared to WT mice [10], which contradicts the decreased inflammation seen in the livers of the $\mathrm{FABP}^{-/-}$mice. The disparity in these results may be due to the difference in cell types found in these 2 organs as well as inflammatory mediators (L. monocytogenes versus Influenza A virus). Our study demonstrates an increase in the bactericidal activity of FABP5-deficient macrophages, suggesting a proinflammatory programming or "M1 phenotype," while the persistence of lung inflammation suggests a deficit in a proresolving programming or "M2 phenotype." Both studies suggest that FABP5 deficiency prevents macrophage polarization towards a proresolving phenotype, favoring a proinflammatory phenotype instead.

This increased proinflammatory programming is in direct contradiction with the findings of Moore et al. [11], who demonstrated that $\mathrm{FABP}^{-/-}$mice were protected from intraperitoneal LPS induced hepatic injury, shown by increased $\mathrm{F} 4 / 80^{+}$macrophage numbers and " $\mathrm{M} 2 \mathrm{mac}$ rophage profiling." These contradictions could be due to the different nature of injury (LPS vs. L. monocytogenes), the activation of different pathways, or the time after injury at which the tissues were observed. Furthermore, as discussed earlier, 2 different types of $\mathrm{F} 4 / 80^{+}$macrophages are present in the mouse liver. It is possible that our study underlines the function of the resident subset while Moore et al. [11] describe the recruited macrophage subset. Interestingly, in both studies, the FABP5-deficient livers were protected from injury.

It has been proposed that FABPs promote anti-inflammatory functions by transporting anti-inflammatory mediators, among them ligands of the nuclear receptor per- 
oxisome proliferator-activated receptor $\gamma(\operatorname{PPAR} \gamma)[33-$ 35]. However, other studies suggest that FABP 5 sequesters these mediators from their target, creating a proinflammatory environment [36-38]. PPAR $\gamma$ is a ligand-dependent transcription factor and a member of the nuclear receptor superfamily [39] that has been shown to have proresolving capabilities [40, 41]. Interestingly, similarly to FABP5 deficiency, a lack of PPAR $\gamma$ in myeloid cells confers resistance to L. monocytogenes infection [42], suggesting that, at least in the case of $L$. monocytogenes infection, PPAR $\gamma$ and FABP5 act in concert to decrease the innate immune response to bacterial infection.

Taken together, our data suggest that FABP5 may represent a valuable target for pharmacological intervention to suppress intracellular bacterial infections such as $L$. monocytogenes. The question that remains is whether inhibiting FABP5 can increase the immunopathology of infected organs. Our novel transgenic mouse model, when crossed onto the FABP5 knockout background, will be an invaluable tool for answering this question.

\section{Acknowledgements}

The authors would like to thank the Biological Resource Center, Mouse Genetic Core and Flow Cytometry facilities for their help in generating the data and reagents presented in this paper.

\section{Statement of Ethics}

All experimental animals used in this study were covered under protocols approved by the Institutional Animal Care and Use Committee of National Jewish Health.

\section{Disclosure Statement}

The authors have no conflicts of interest to declare.

\section{Funding Sources}

This work was partially supported by Flight Attendant Medical Research Institute (FAMRI) grants 103151 and 150041 (to F.G.), in particular the generation of Rosa26-STOPflox-Fabp5-2A-YFP transgenic mice and crossing onto LysM-Cre mice.

\section{Author Contributions}

F.G. designed the research studies; D.M.R., D.T.P., M.J.C., A.L.O., and F.G. conducted the experiments; D.M.R., and F.G. acquired the data, D.M.R. and F.G. analyzed the data, A.-L.P. provided the reagents, and F.G. wrote the manuscript.

\section{References}

1 Gaillard JL, Berche P, Mounier J, Richard S, Sansonetti P. In vitro model of penetration and intracellular growth of Listeria monocytogenes in the human enterocyte-like cell line Caco-2. Infect Immun. 1987 Nov;55(11): 2822-9.

2 Cossart P, Toledo-Arana A. Listeria monocytogenes, a unique model in infection biology: an overview. Microbes Infect. 2008 Jul;10(9): 1041-50.

3 Unanue ER. Inter-relationship among macrophages, natural killer cells and neutrophils in early stages of Listeria resistance. Curr Opin Immunol. $1997 \mathrm{Feb}$;9(1):35-43.

4 Shiloh MU, MacMicking JD, Nicholson S, Brause JE, Potter S, Marino M, et al. Phenotype of mice and macrophages deficient in both phagocyte oxidase and inducible nitric oxide synthase. Immunity. 1999 Jan;10(1): 29-38.

5 Hart CM, Tolson JK, Block ER. Supplemental fatty acids alter lipid peroxidation and oxidant injury in endothelial cells. Am J Physiol. 1991 Jun;260(6 Pt 1):L481-8.
6 Curi R, de Siqueira Mendes R, de Campos Crispin LA, Norata GD, Sampaio SC, Newsholme P. A past and present overview of macrophage metabolism and functional outcomes. Clin Sci (Lond). 2017 Jun;131(12): 1329-42.

7 Zimmerman AW, Veerkamp JH. Fatty-acidbinding proteins do not protect against induced cytotoxicity in a kidney cell model. Biochem J. 2001 Nov;360(Pt 1):159-65.

8 Siegenthaler G, Hotz R, Chatellard-Gruaz D, Didierjean L, Hellman U, Saurat JH. Purification and characterization of the human epidermal fatty acid-binding protein: localization during epidermal cell differentiation in vivo and in vitro. Biochem J. 1994 Sep;302(Pt 2):363-71.

9 Holler J, Zakrzewicz A, Garn H, Hirschburger M, Kummer W, Padberg W, et al. Increased expression of epidermal fatty acid-binding protein by alveolar macrophages during acute rejection of rat lungs. APMIS. 2010 Oct; 118(10):791-800.
10 Gally F, Kosmider B, Weaver MR, Pate KM Hartshorn KL, Oberley-Deegan RE. FABP5 deficiency enhances susceptibility to H1N1 influenza A virus-induced lung inflammation. Am J Physiol Lung Cell Mol Physiol. 2013 Jul;305(1):L64-72.

11 Moore SM, Holt VV, Malpass LR, Hines IN, Wheeler MD. Fatty acid-binding protein 5 limits the anti-inflammatory response in murine macrophages. Mol Immunol. 2015 Oct; 67(2 2 Pt B):265-75.

12 Valenzuela DM, Murphy AJ, Frendewey D, Gale NW, Economides AN, Auerbach W, et al. High-throughput engineering of the mouse genome coupled with high-resolution expression analysis. Nat Biotechnol. 2003 Jun; 21(6):652-9.

13 Tripp CS, Wolf SF, Unanue ER. Interleukin 12 and tumor necrosis factor alpha are costimulators of interferon gamma production by natural killer cells in severe combined immunodeficiency mice with listeriosis, and interleukin 10 is a physiologic antagonist. Proc Natl Acad Sci USA. 1993 Apr;90(8):3725-9. 
14 D’Orazio SE, Troese MJ, Starnbach MN. Cytosolic localization of Listeria monocytogenes triggers an early IFN-gamma response by $\mathrm{CD} 8+\mathrm{T}$ cells that correlates with innate resistance to infection. J Immunol. 2006 Nov; 177(10):7146-54.

15 Serbina NV, Shi C, Pamer EG. Monocyte-mediated immune defense against murine Listeria monocytogenes infection. Adv Immunol. 2012;113:119-34.

16 Buchmeier NA, Schreiber RD. Requirement of endogenous interferon-gamma production for resolution of Listeria monocytogenes infection. Proc Natl Acad Sci USA. 1985 Nov; 82(21):7404-8.

17 Huang S, Hendriks W, Althage A, Hemmi S, Bluethmann H, Kamijo R, et al. Immune response in mice that lack the interferon-gamma receptor. Science. 1993 Mar;259(5102): $1742-5$.

18 Pfeffer K, Matsuyama T, Kündig TM, Wakeham A, Kishihara K, Shahinian A, et al. Mice deficient for the $55 \mathrm{kd}$ tumor necrosis factor receptor are resistant to endotoxic shock, yet succumb to L. monocytogenes infection. Cell. 1993 May;73(3):457-67.

19 Rothe J, Lesslauer W, Lötscher H, Lang Y, Koebel P, Köntgen F, et al. Mice lacking the tumour necrosis factor receptor 1 are resistant to TNF-mediated toxicity but highly susceptible to infection by Listeria monocytogenes. Nature. 1993 Aug;364(6440):798-802.

20 Kopf M, Baumann H, Freer G, Freudenberg M, Lamers M, Kishimoto T, et al. Impaired immune and acute-phase responses in interleukin-6-deficient mice. Nature. 1994 Mar; 368(6469):339-42.

21 Nakane A, Numata A, Minagawa T. Endogenous tumor necrosis factor, interleukin-6, and gamma interferon levels during Listeria monocytogenes infection in mice. Infect Immun. $1992 \mathrm{Feb}$;60(2):523-8.

22 Nakane A, Yamada K, Hasegawa S, Mizuki D Mizuki M, Sasaki S, et al. Endogenous cytokines during a lethal infection with Listeria monocytogenes in mice. FEMS Microbiol Lett. 1999 Jun;175(1):133-42.

23 Regan T, MacSharry J, Brint E. Tracing innate immune defences along the path of Listeria monocytogenes infection. Immunol Cell Biol. 2014 Aug;92(7):563-9.
24 Dussurget $\mathrm{O}$, Bierne $\mathrm{H}$, Cossart $\mathrm{P}$. The bacterial pathogen Listeria monocytogenes and the interferon family: type I, type II and type III interferons. Front Cell Infect Microbiol. 2014 Apr;4:50.

25 Dai WJ, Köhler G, Brombacher F. Both innate and acquired immunity to Listeria monocytogenes infection are increased in IL-10-deficient mice. J Immunol. 1997 Mar;158(5): 2259-67.

26 Silva RA, Appelberg R. Blocking the receptor for interleukin 10 protects mice from lethal listeriosis. Antimicrob Agents Chemother. 2001 Apr;45(4):1312-4.

27 Foulds KE, Rotte MJ, Seder RA. IL-10 is required for optimal CD8 T cell memory following Listeria monocytogenes infection. J Immunol. 2006 Aug;177(4):2565-74.

28 Pan Y, Tian T, Park CO, Lofftus SY, Mei S, Liu $\mathrm{X}$, et al. Survival of tissue-resident memory $\mathrm{T}$ cells requires exogenous lipid uptake and metabolism. Nature. 2017 Mar;543(7644):252-6

29 McLennan G, Oberley LW, Autor AP. The role of oxygen-derived free radicals in radiation-induced damage and death of nondividing eucaryotic cells. Radiat Res. 1980 Oct; 84(1):122-32.

30 Perkins EH, Nettesheim P, Morita T. Radioresistance of the engulfing and degradative capacities of peritoneal phagocytes to kiloroentgen x-ray doses. J Reticuloendothel Soc. 1966 May;3(1):71-82.

31 Kinoshita M, Uchida T, Sato A, Nakashima M, Nakashima H, Shono S, et al. Characterization of two F4/80-positive Kupffer cell subsets by their function and phenotype in mice. J Hepatol. 2010 Nov;53(5):903-10.

32 Ikarashi M, Nakashima H, Kinoshita M, Sato A, Nakashima M, Miyazaki H, et al. Distinct development and functions of resident and recruited liver Kupffer cells/macrophages. J Leukoc Biol. 2013 Dec;94(6):1325-36.

33 Hertzel AV, Bernlohr DA. Regulation of adipocyte gene expression by polyunsaturated fatty acids. Mol Cell Biochem. 1998 Nov; 188(1-2):33-9.

34 Wolfrum C, Borrmann CM, Borchers T, Spener F. Fatty acids and hypolipidemic drugs regulate peroxisome proliferator-activated receptors alpha - and gamma-mediated gene expression via liver fatty acid binding protein: a signaling path to the nucleus. Proc Natl Acad Sci USA. 2001 Feb;98(5):2323-8.
35 Tan NS, Shaw NS, Vinckenbosch N, Liu P, Yasmin R, Desvergne B, et al. Selective cooperation between fatty acid binding proteins and peroxisome proliferator-activated receptors in regulating transcription. Mol Cell Biol. 2002 Jul;22(14):5114-27.

36 Helledie T, Antonius M, Sorensen RV, Hertzel AV, Bernlohr DA, Kølvraa S, et al. Lipidbinding proteins modulate ligand-dependent trans-activation by peroxisome proliferatoractivated receptors and localize to the nucleus as well as the cytoplasm. J Lipid Res. 2000 Nov;41(11):1740-51.

37 Makowski L, Boord JB, Maeda K, Babaev VR, Uysal KT, Morgan MA, et al. Lack of macrophage fatty-acid-binding protein $\mathrm{aP} 2$ protects mice deficient in apolipoprotein $\mathrm{E}$ against atherosclerosis. Nat Med. 2001 Jun;7(6):699705

38 Reynolds JM, Liu Q, Brittingham KC, Liu Y, Gruenthal M, Gorgun CZ, et al. Deficiency of fatty acid-binding proteins in mice confers protection from development of experimental autoimmune encephalomyelitis. J Immunol. 2007 Jul;179(1):313-21.

39 Nuclear Receptors Nomenclature Committee. A unified nomenclature system for the nuclear receptor superfamily. Cell. 1999 Apr; 97(2):161-3.

40 Yoon YS, Kim SY, Kim MJ, Lim JH, Cho MS, Kang JL. PPAR $\gamma$ activation following apoptotic cell instillation promotes resolution of lung inflammation and fibrosis via regulation of efferocytosis and proresolving cytokines. Mucosal Immunol. 2015 Sep;8(5):1031-46.

41 Gautier EL, Chow A, Spanbroek R, Marcelin G, Greter M, Jakubzick C, et al. Systemic analysis of PPAR $\gamma$ in mouse macrophage populations reveals marked diversity in expression with critical roles in resolution of inflammation and airway immunity. J Immunol. 2012 Sep;189(5):2614-24.

42 Abdullah Z, Geiger S, Nino-Castro A, Böttcher JP, Muraliv E, Gaidt M, et al. Lack of PPAR $\gamma$ in myeloid cells confers resistance to Listeria monocytogenes infection. PLoS One. 2012;7(5):e37349. 